\title{
CHANGES IN SOMATIC PARAMETERS AND DYNAMIC BALANCE IN FEMALE RHYTHMIC GYMNASTS OVER A SPACE OF TWO YEARS
}

\author{
Changes in somatic and balance abilities of female gymnasts
}

\author{
TATIANA POLISZCZUK ${ }^{1}$, DARIA BRODA ${ }^{1}$, DMYTRO POLISZCZUK ${ }^{2}$ \\ The Jozef Pilsudski University of Physical Education in Warsaw, Faculty of Physical Education, \\ Department of Gymnastics and Sport for All', Department of Physiology ${ }^{2}$
}

Mailing address: Tatiana Poliszczuk, The Jozef Pilsudski University of Physical Education in Warsaw, Department of Gymnastics and Sport for All, 34 Marymoncka Street, 00-968 Warszawa, tel.: +48228340431 ext. 373, fax: +48 22 8651080, e-mail: tatiana.poliszczuk@awf.edu.pl

\begin{abstract}
Introduction. Body build and the ability to maintain balance play an important role in the development and improvement of specialised motor habits and complex technical elements necessary to achieve significant sporting results in rhythmic gymnastics. The aim of this study was to determine changes in the level of ability to maintain dynamic balance and in the construction of somatic young female rhythmic gymnasts during a period of two year training. Material and methods. The research material consisted of 13 girls. When the first measurements were taken gymnasts were aged $7-12$ years. In the study we utilised posturography and the Heath-Carter Anthropometric Somatotype Method. The analysis of the study showed that there were statistically significant differences $(\mathrm{p}<0.05)$ in the values of the dynamic balance indicators of the gymnasts' bodies in all three consecutive measurements over a course of years. Results and conclusions. It was noted that as the young gymnasts progressed in their training, their ability to maintain dynamic balanced increased. Based on the characteristics of the model, we developed an exemplary set of dynamic balance of rhythmic gymnasts. The somatotype of the tested athletes surveyed had been changing in the direction of increase in the proportion of components of endomorphy and mesomorphy. The balance ability of rhythmic gymnasts stabilised during their puberty associated with changes in body proportions ratio i.e.: height, weight and somatotype. The results and conclusions drawn can be an important part of selection and choice and can be used to control the dynamic balance in rhythmic gymnastics.
\end{abstract}

Key words: rhythmic gymnastics, body balance, posturography, body build, somatotype, selection and choice in sports

\section{Introduction}

The ability to balance the body plays an important role in the shaping and improving specialised motor habit, as it is the basis for the mastery of complex technical elements necessary to achieve significant sporting results.

Physical fitness depends on innate predispositions and environmental factors, such as primarily training. With the development of the human body, and over time this factor becomes increasingly important in the development of the ability to maintain body balance [1,2]. The level of coordination is significantly affected by the ability to stabilise and maintain the human body in a balanced position. Experts have shown that there are relationships between the proper functioning of the balance and other coordination motor skills. These relationships were observed in athletes practicing sports with difficult and complex techniques [3]. These include rhythmic gymnastics, which is an early discipline of sport (recruitment starts at the age of 5).

During competitions gymnasts compete in four individual events. Each event lasts one and a half minutes. At that time the athlete performs 20-22 elements of static and dynamic balance. Looking at the issue from the point of view of sporting technique, the ability to maintain body balance is one of the most significant motor skills in this discipline.

Body build is also an important element of choice and selection in most of sporting competitions, as it determined not only the overall, but also the special physical fitness.

Many authors point to the importance of morphology build in achieving sporting success and the level of that significance depends on the sporting discipline $[4,5]$. In rhythmic gymnastics success is largely contingent upon the somatic build along with suppleness as well as explosive [6, 7].

Rhythmic gymnastics is becoming more and more popular, not only as a competitive sport, but also as a means of recreation and rehabilitation. Practicing gymnastics improves the posture and physiological functions [8] and the coordination capacity [9]. In the case of the deaf and the blind, a special program of gymnastic exercises enables significant improvement in the ability to balance the body $[10,11]$.

It should be noted that there is a great deal of interest on the part of specialists in Poland and worldwide in problem of growth, development and diagnostics of capabilities to maintain balance in technical and aesthetic sports $[1,2,3,10]$. Despite this, the problem is still present, especially because of an insufficient number of publications on dynamic balance in gymnastics and still ongoing discussions about the formation of the balance in the ontogeny.

The aim of this study was to determine changes in the level of ability to maintain dynamic balance and in the somatic body build of young rhythmic gymnasts over two years of sports training. 


\section{Material and methods}

The survey was conducted three times during the start of the annual sporting training cycle. The first measurement concerned initial diagnosis of indicators characterising dynamic balance and determination of somatotype of the rhythmic gymnasts (stage I). After a year of training the very same measurements were repeated (stage II); the same happened after two years (stage III). At the time of the first measurements the study group consisted of 24 gymnasts aged from 7 to 12 years. A year later, there were 19 gymnasts aged $8-13$ years, but by the next year, this number decreased to 13. Some of the girls gave up gymnastics as a result of natural selection. As a result of the above-described changes, this paper presents results of thirteen gymnasts participating in the three consecutive measurements. The athletes trained at various Warsaw based clubs, and represented the top athletes of their respective clubs. At the time of the final measurement the girls were aged 9-14 years, and their training experience was $4.7 \pm 1.57$ years (Tab. 1 ).

Table 1. Somatic characteristics of gymnasts at individual stages of the study $(n=13)$

\begin{tabular}{|l|c|c|c|c|c|c|}
\hline \multirow{2}{*}{ Indices } & \multicolumn{2}{|c|}{ Stage I } & \multicolumn{2}{c|}{ Stage II } & \multicolumn{2}{c|}{ Stage III } \\
\cline { 2 - 7 } & $\mathbf{x}$ & \pm SD & $\mathbf{x}$ & \pm SD & $\mathbf{x}$ & \pm SD \\
\hline Age (years) & 9.79 & 1.41 & 11.19 & 1.45 & 12.1 & 1.51 \\
\hline Height $(\mathrm{cm})$ & 136.8 & 7.62 & 144.3 & 8.27 & 149.7 & 7.37 \\
\hline Weight $(\mathrm{kg})$ & 29.43 & 5.45 & 35.71 & 7.66 & 38.08 & 8.06 \\
\hline BMI & 15.58 & 1.29 & 16.95 & 1.97 & 16.82 & 2.35 \\
\hline
\end{tabular}

To characterise the somatic body build of the girls we used the Heath-Carter Anthropometric Somatotype Method based on Sheldon's classic concept of the three body build components [12].

The method of posturography based on statokinesiometric tests was used to assess dynamic balance of the gymnasts. For the purpose of the study we used a "Posturograph" manufactured by "PRO-MED", which consists of a posturographic platform and a computer program to evaluate the functional state of the human balance organ [13]. As part of the dynamic balance test the subject was required to move her body's centre of gravity (COG), so that its projection was maintained at all times in a square appearing on the monitor, which constantly moved in eight directions (Fig. 1).

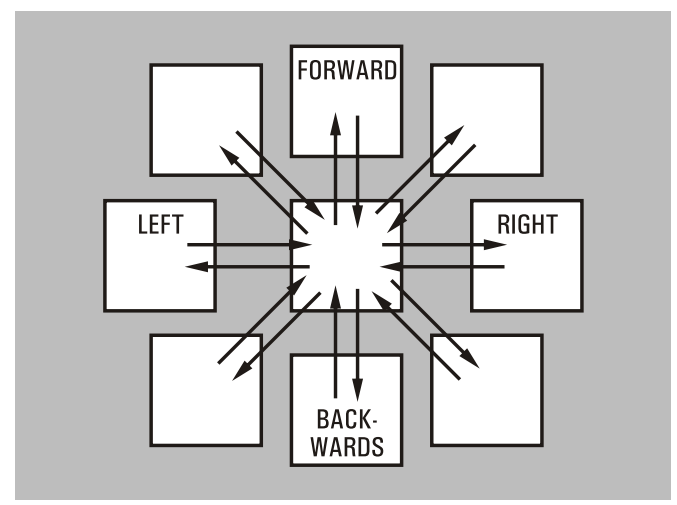

Figure 1. Directions of movement of the square which is placed on the monitor
The subject observes her current COG projection position on the monitor and corrects her posture to keep this point in a given limiting area. We calculated: the arrival time (s), and the path (\%) of the COG projection to the designated point and the duration of stay at that point (\%). We also used model characteristics of dynamic balance (modified Cartesian coordinate system) developed based on the best performance of the tested athletes.

The results were statistically analysed using STATISTICA 8.0 PL. Due to the high dispersion of the data, logarithmic transformation was applied. Normality of distribution of the traits was examined using the Shapiro - Wilk test. Significance of differences between the mean values was determined using analysis of variance for repeated measurements ANOVA. A post hoc Tukey's test was conducted to investigate the effects of substantial interactions at significance level $<0.05$. Detailed analyses also covered significant parameters of dynamic balance in the directions: forward, right, back, left, and three somatotype components as well as the BMI.

\section{Results}

Analysis of the body build survey results allowed us to determine somatotypes of the rhythmic gymnasts, as well as changes over the next two years (Fig. 2, Fig. 3, Fig. 4). Somatotypes placed in the centre of the Sheldon somatogram are characterised by equal share of all the components in the body build. The closer to a vertex and the further from the centre of the Sheldon somatogram, the greater the share of the component in the creation of somatotype.

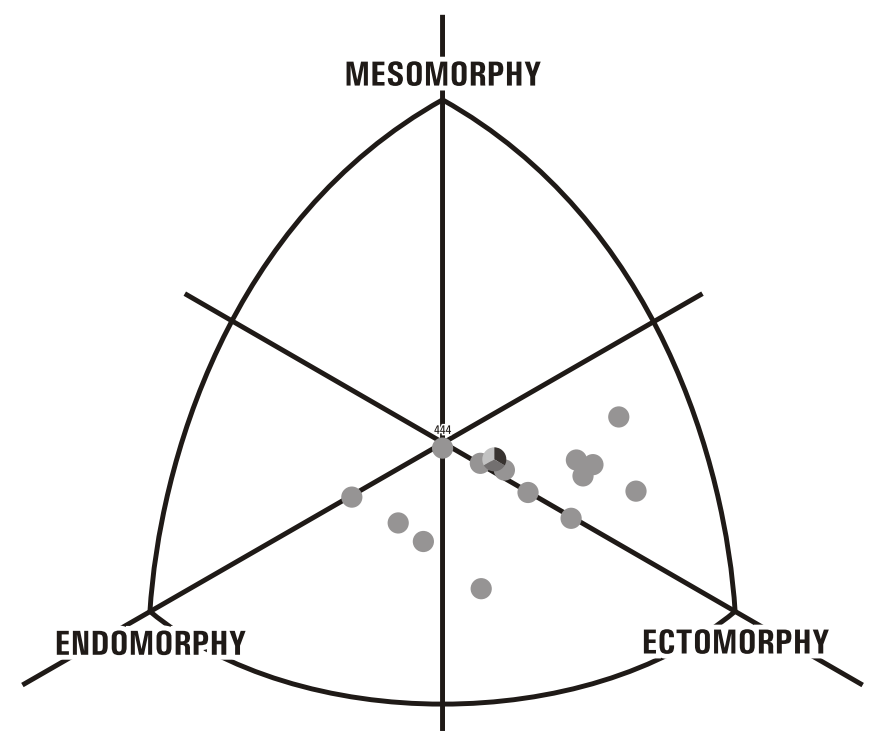

Figure 2. Somatotypes of gymnasts at stage I of the study $(n=13)$ 


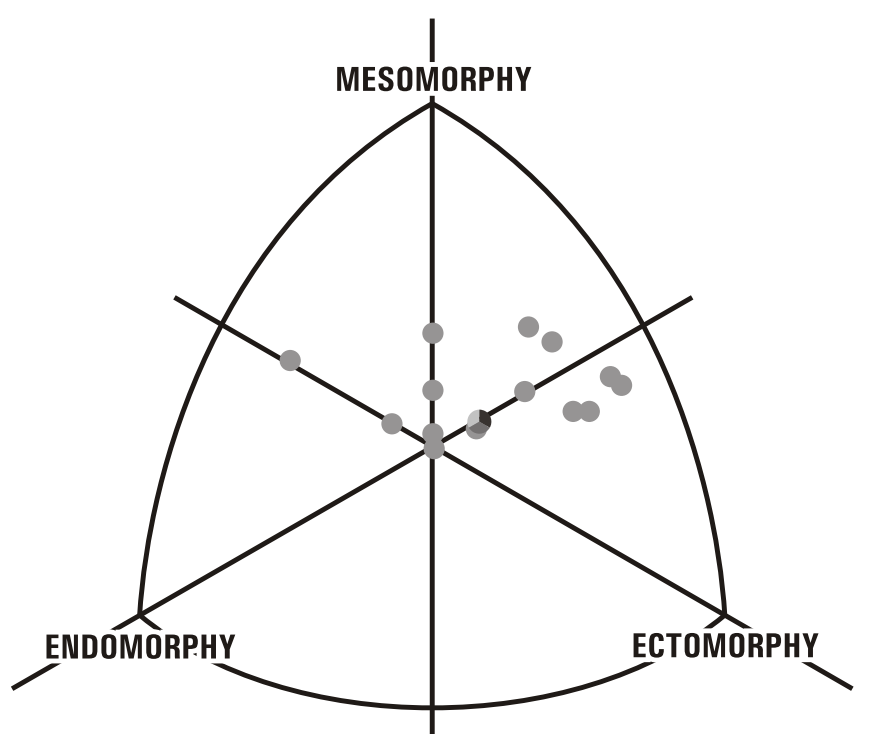

Figure 3. Somatotypes of gymnasts at stage II of the study $(n=13)$

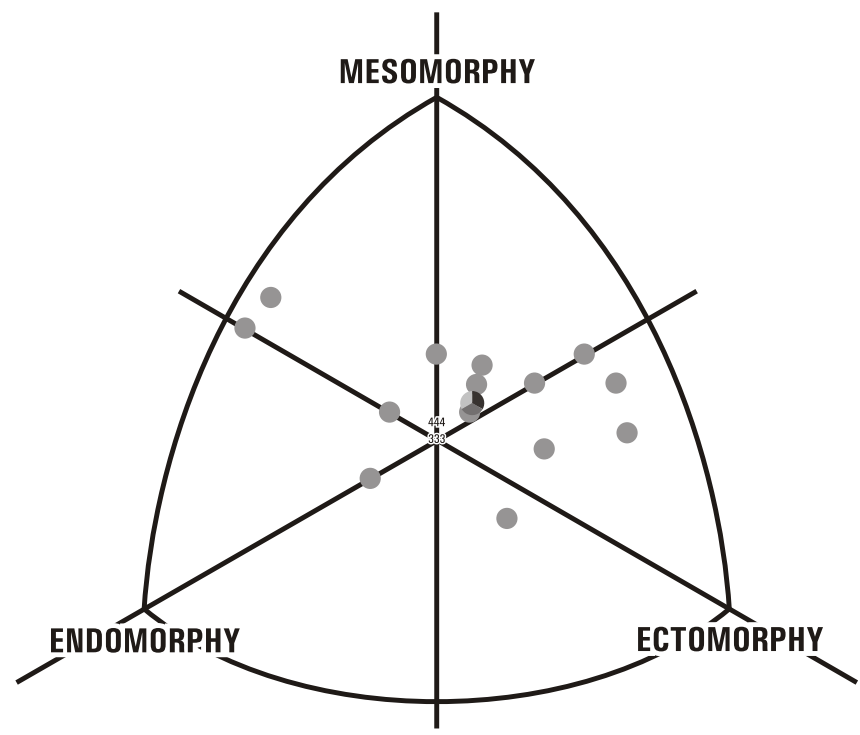

Figure 4. Somatotypes of gymnasts at stage III of the study $(n=13)$

On the first somatogram most of the somatotypes are located in the ectomorphy part (Fig. 2). This demonstrates the significant share of the slenderness component in the body build of the gymnasts aged 7-12 years. The average value of BMI in this group was $15.58 \pm 1.27$. On the second somatogram, somatotypes of the athletes were placed in the ectomorphy and mesomorphy part (Fig. 3). Within one year, the component of mesomorphy (i.e. obesity) increased substantially $(\mathrm{p}<0.01)$. This is also confirmed by the increase of the BMI up to $16.95 \pm 1.97$ $(p<0.01)$. After the second year of training, most of the girls' somatotypes fell in the middle, which is determined by the growth of other components in addition to the slenderness component. The majority of somatotypes of the tested gymnasts fell within the ectomorphy and mesomorphy part, but the results are not as homogeneous (Fig. 4). The differences were to a significant extent caused by a substantial increase in the endomorphy component in four of the athletes. The value of BMI in the study group was $16.82 \pm 2.35$. Somatotypes of girls changed over the two years of training.

Changes were observed $(\mathrm{p}<0.05)$ in most of the anthropometric characteristics. There were no statistically significant differences in rates of skinfolds thickness: on shoulders, under the shoulder blade or the lower leg over the period of two years. Changes between the first and the third component of endomorphy measurement were detected $(\mathrm{p}<0.01)$ as well as in the weight to height ratio-BMI $(\mathrm{p}<0.05)$.

In addition to the overall body build, significant factors in selection of athletes in rhythmic gymnastics include general fitness and special coordination motor abilities.

On the basis of the best results in the study group (13 gymnasts), at subsequent stages model characteristics of the observed dynamic balance parameters were developed (arrival time (s), path (\%) of the COG projection to the designated point and duration of stay (\%) gymnasts COG projection of the set point selected on the monitor). The first model corresponded to measurements at the first stage of the study, the second one corre-sponded to measurements after one year of training (stage II) and the third one corresponded to measurements after two years of training (stage III).

For all three characteristics of model arrival time of the COG projection, it was observed that the weakest results were in the following positions: to left and to the right, as quick transition to designated points is a difficult task, and in the case of feedback it needs a high level of eye and movement coordination. The result is all the better, the smaller the value of the measurement. The best results were recorded while returning from one position to the initial position, which showed that the gymnasts had a habit of rapid correction of posture to the stable and secure level. The weakest results of the arrival time of the COG projection to the designated point occurred during the first stage of the study. Between the results of the first and the third stage of the study an improvement in the value of dynamic balance parameters in the left direction was noted $(p<0.05)$.

On the basis of the best results in subsequent years, in the path (\%) of the COG projection to a certain point, taking into account all the girls, three model characteristics were developed. The higher the value of the indicator the worse the result, while its minimum value indicated $100 \%$. It was observed that in the case of the three model values the most difficult directions to reach a designated point, were to the right and to the left (Fig. 5, Fig. 6, Fig. 7). The weakest results of path (\%) of the COG projection to the designated point occurred at the first stage (Fig. 5). In the case of model characteristics 2 and 3, most of the results fell below 150\% which could not be observed in the first test (Figs. 6, 7). A statistically significant improvement $(p<0.05)$ was observed only in the direction to the left. 


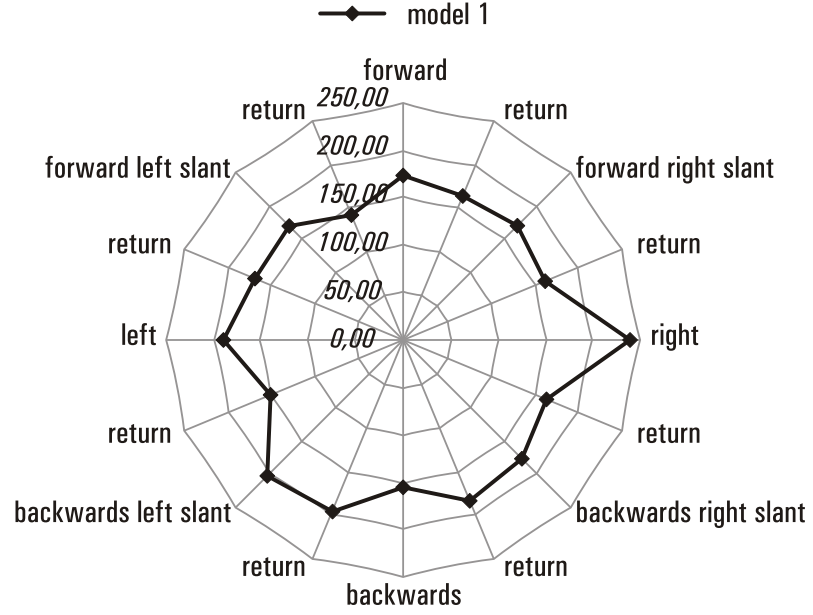

Figure 5. Model characteristics of the path (\%) of the COG projection at stage I $(n=13)$

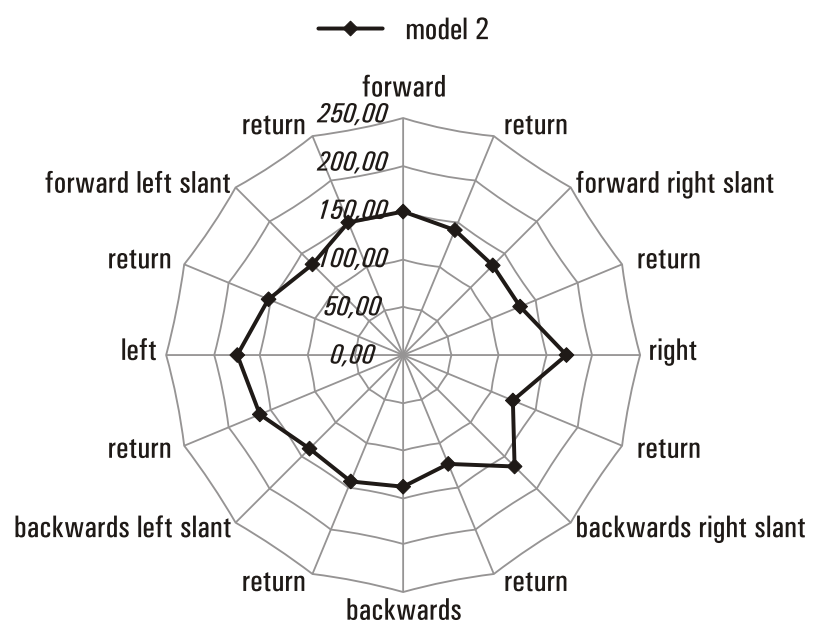

Figure 6. Model characteristics of the path (\%) of the COG projection at stage II $(n=13)$

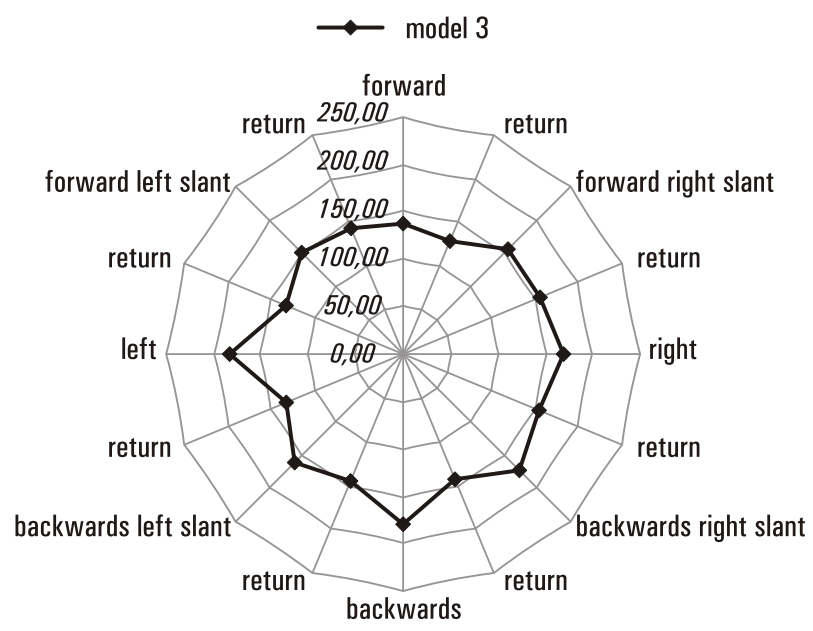

Figure 7. Model characteristics of the path (\%) of the COG projection at stage III $(n=13)$
Other model characteristic created on the basis of the best results in subsequent years relate to index showing how long COG projection stayed at individual points. $100 \%$ is the maximum value. In this case, the higher the value of the parameter, the better is the result. In model 1 according to the eight indicators regarding various directions, the score was above $95 \%$ (Fig. 8). However, at stage II, eleven scores were above this value (Fig. 9). Model 3 comprises of ten indices above 95\%, and as many as seven of them were maximum values of 100\% (Fig. 10). Each year, the duration of stay of COG projection at certain points, improved, and in the final year, it had the highest value of $100 \%$ in seven out of sixteen directions. However, this improvement was statistically significant $(p<0.05)$ only in the left direction.

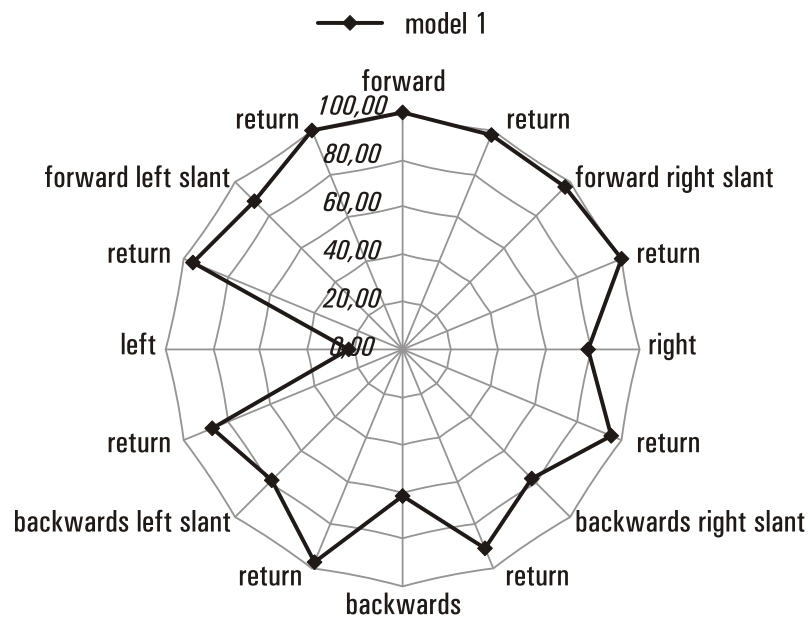

Figure 8. Model characteristics of the duration of stay (\%) of the COG projection at stage I $(n=13)$

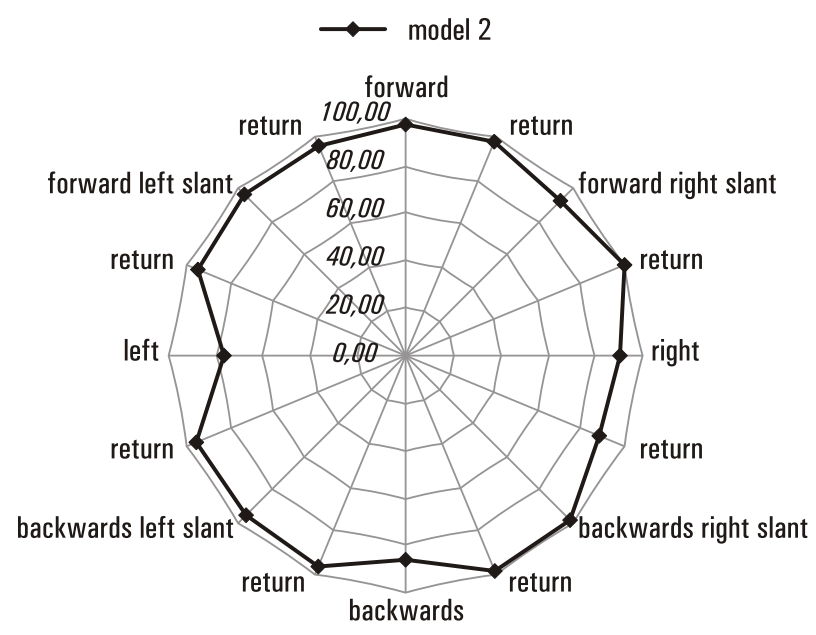

Figure 9. Model characteristics of the duration of stay (\%) of the COG projection at stage II $(n=13)$ 


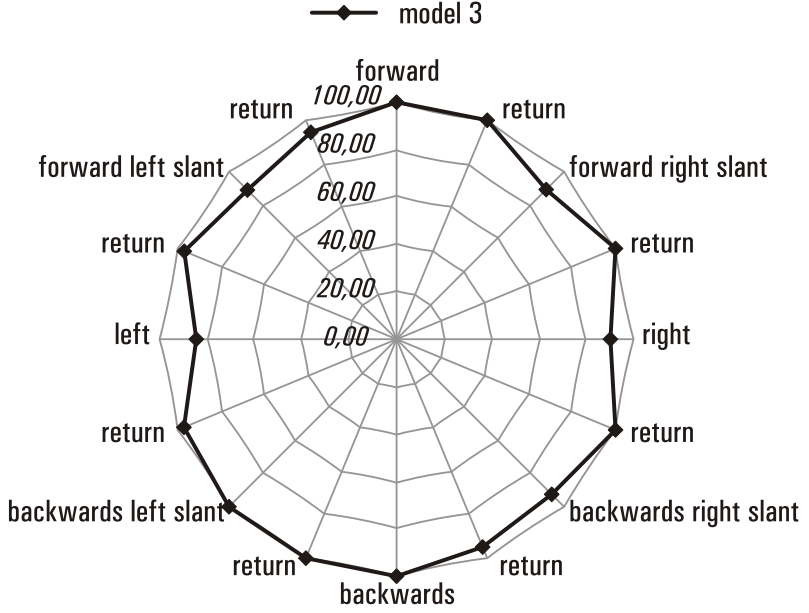

Figure 10. Model characteristics of the duration of stay (\%) of the COG projection at stage III $(n=13)$

\section{Discussion}

In rhythmic gymnastics in addition the assessment of the difficulty of technical elements, also the artistic impression is subject to evaluation. This assessment covers synchronisation of movements with the music, the aesthetics of movement, choreography and placement on the board, as well as the appearance of athletes. Slender figure is important as well as body flexibility - these are the priorities in selection and choice of athletes for the sport. [7] This is confirmed by measurements made for the purposes of this paper in the first year of the study. The arithmetic mean of BMI in the subjects with training experience of $2.7 \pm 1.57$ years was $15.58 \pm 1.29$. At each stage of the study the average BMI of the tested gymnasts was in the lower limits of norm [14, 15], which demonstrates the slenderness of their bodies. These girls are healthy (which is confirmed by statements of regularly conducted medical examinations), at full strength and able to practice, and at the same time have the necessary abilities to practice the sport and achieve high sporting performance in the future. Still, rhythmic gymnastics coaches are often accused of lack of professional approach to weight loss of athletes [16]. The problem in gymnastics sports is still controversial, because it contributes to mental illnesses such as bulimia or anorexia, and the lack of observation and response to signs of their presence has tragic consequences. Scientists, in disciplines that emphasise slenderness, have distinguished "the female athlete triad syndrome" (FTS), reflected in the form of nutritional disorders, occurrence of late menstrual period compared to peers and osteoporosis [17].

Analysis of the results shows that over the two years somatotypes of some athletes had changed considerably. Definitely, the height and weight of the body, and the component mesomorph had increased. Changes associated with the beginning of puberty of the tested gymnasts were also observed. Some scientists demonstrated in their studies that rhythmic gymnastics athletes mature about $2-3$ years later than their peers $[18,19]$. In the first stage of the study somatotypes of the girls were very close due to the selection for the sport, but as growth and maturation of their bodies progressed, body of each athlete changed according to the individual circumstances of development. The rate of growth could have been influenced by training loads and stress of the competition [19, 20].

One can anticipate that future studies in one year's time, because of the constant trend of unfavourable changes in body proportions of individual gymnasts, the number of respondents may be reduced due to the sporting selection. Verification of this supposition will require additional studies.

The phenomenon of such natural selection in rhythmic gymnastics athletes in puberty may be due to methodological errors in the selection for the sport, as well as reasons of subjective nature (motivation, personality traits, etc.). It should also be taken into account that girls, who in childhood are slim, do not necessarily meet the requirements of judges when they are older. The increase in height and body weight contributes to the potential problems of coordination, which results in reducing the learning ability and performance of complex technically specialised components. Due to the fact that the majority of somatic characteristics of the body are determined genetically, therefore when selecting candidates for gymnastics, in addition to the general outlook of the candidates, one also needs to pay attention to the somatotype of their parents [21]. In some countries, special programs are developed to discover gymnastic talents through choice and selection [22].

In rhythmic gymnastics, in order to maintain the correct posture it is important to apply systematising exercises that involve balance, strength and flexibility training and other specific elements evenly on the left and right side. Right sided lateralization was detected in the examined girls. Positive, statistically significant changes in the ability to maintain dynamic balance were found in three examined indexes towards the left. This improvement resulted from the use of symmetric training, which has a beneficial effect on the human body, and is also confirmed by other authors [23].

It should also be noted that the two-year training cycle of the rhythmic gymnasts was not focused solely on the development of balance. Gymnastics training is focused on comprehensive development of young athletes' physical fitness. In order to perform such difficult elements like twine jumping, weight on one leg forward and back, and a series of pirouettes it is necessary to improve the ability to maintain balance, but also jumping ability and flexibility. The studies have shown that two year training has had a beneficial effect on the ability to maintain balance in gymnasts aged 7-12 years, but at this stage of the study it cannot be established with certainty to what extent. In addition to environmental conditions $[1,2]$, to obtain a level of balance particular for a person, various genetic factors are important [21].

Both, studies on the ability of balance and on body build, proved to be the most important factors affecting the success of sports in rhythmic gymnastics. The results of studies can help doctors and sports trainers to create a training system, starting with choice, through selection and improvement of the athletic achievements in rhythmic gymnastics.

\section{Acknowledgements}

The research was accomplished within the framework of statutory research of the Josef Pilsudski University of Physical Education in Warsaw - DM. 11 - financed by the Ministry of Science and Higher Education.

\section{Conclusions}

1. Somatotype of rhythmic gymnasts aged $7-12$ changes over two years of sports training. During this period, in creating somatotype with age there is a decrease the ectomorphy component and an increase in the share of the endomorphy and mesomorphy component.

2. The tested rhythmic gymnasts were characterised by ability to maintain dynamic balance. Based on models 
developed, exemplary set of balance indices in rhythmic gymnasts were developed. Improvements $(\mathrm{p}<0.05)$ were observed in subsequent years: toward the left in the following indices: the arrival time, the path and the duration of stay of COG projection.

3. It was observed that there was a tendency to improve the ability to maintain dynamic balance with increasing length of training experience of young gymnasts.

4. During puberty, which is associated with the change in body proportions, height, weight as well as somatotype, there is stagnation in the level of ability of rhythmic gymnasts to maintain body balance.

\section{Literature}

1. Onell, A. (2000). The vertical ground reaction force for analysis of balance? Gait Posture 12(1), 7-13.

2. Kochanowicz, K. \& Kucharska E. (2010). Body balance in children aged 11-13 years and the process of physical education. Pol. J. Sport Tourism 17, 87-96.

3. Bressel, E., Yonker J.C., Kras J. \& Heath E. (2007). Comparison of static and dynamic balance in female collegiate soccer, basketball, and gymnastics athletes. J Athl Train. 42(1), 42-46.

4. Claessens, A.L., Beunen G. \& Malina R.M. (2000). Anthropometry, physique, body composition and maturity. In N. Armstrong \& Van Mechelen (Eds.), Paediatric Exercise Science and Medicine (pp. 11-22). Oxford: Oxford University Press.

5. Leone, M., Lariviere G. \& Comtois A. (2002, June). Discriminant analysis of anthropometric and biomotor variables among elite adolescent female athletes in four sports [Abstract]. EJSS. 6, 443 - 449. Retrieved October 17, 2012, from PubMed database on the World Wide Web: http//www. pubmed.gov.

6. Cleassens, A., Delbroek W. \& Lefevre J. (2007). The use of different prediction equation for the assessment of body composition in young female gymnasts - is the best equation. In T. Jurimae \& A. Hills (Eds.), Body composition assessment in children and adolescents. Med. Sport Sci. Basel. Karger 44, 138-154.

7. Douda, H., Toubekis A., Avloniti A. \& Tokmakidis S. (2008, marzec). Physiological and anthropometric determinants of rhythmic gymnastics performance [Abstract] JSPP 3(1), 41-54. Retrieved October 17, 2012, from PubMed database on the World Wide Web: http//www.pubmed.gov.

8. Cui, Yu. (2004, marzec). Effect of Rhythmic Gymnastic Exercise on Female University Students' Physique [Abstract]. SIPE. 03. Retrieved October 17, 2012, from Google Scholar database on the World Wide Web: http//www. scholar.google.pl DOI: STYB.0.2004-03-021.

9. Poliszczuk, T. \& Broda D. (2010). Somatic constitution and the ability to maintain dynamic body equilibrium in girls practicing rhythmic gymnastics. Pediatric Endocrinology Diabetes and Metabolism 16(2), 94-99.

10. Fotiadou, E., Giagazoglou P., Kokaridas D., Angelopoulou N., Tsimaras V. \& Tsorbatzoudis C. (2002). Effect of rhythmic gymnastics on the dynamic balance of children with deafness. Eur J Spec Needs Educ. 17(3), 301-309. DOI:10.1080/ 08856250210162211.

11. Poliszczuk, T., Rutkowska I. (2006). Comparative analysis of the balance ability in blind girls and artistic gymnasts. In J. Nowocień (Ed.), Social and educational face of Olympism. Olympic Movement and disabled athletes. Vol. I (pp.157163). Warszawa: AWF. [in Polish]
12. Heath, B.H. \& Carter J.E.L. (1990). Somatotyping - Development and Applications. New York: Cambridge University Press.

13. Olton, J. (2004). The Posturograph. A system for testing and evaluation of the balance and eye-movement coordinationInstruction. Pro-Med. [in Polish]

14. Cole, T.J., Bellizzi M.C., Flegal K.M. \& Dietz W.H. (2000). Establishing a standard definition for child overweight and obesity worldwide: international survey. Bmj. 320 (7244), 1240-1243.

15. Cole, T.J., Flegal K.M., Nicholls D. \& Jackson A.A. (2007). Body mass index cut offs to define thinness in children and adolescents: international survey. Bmj. 335(7612), 194-201. DOI: 10.1136/bmj.39238.399444.55.

16. Xiaoming, G., Yancheng G., ShuoKuang Li G., Huixin F. \& Ma Qiaolan. (1994, styczeń). Nutritional Monitor and Diet Adaptation of National Rhythmical Gymnastics Team before Competition [Abstract]. Journal of Beijing University of Physical Education 01. Retrieved October 17, 2012, from Google Scholar database on the World Wide Web: http//www.scholar. google.pl DOI: BJTD.0.1994-01-010.

17. Weinstein, Y. \& Weinstein A. (2012, luty). Energy balance, body composition and the female athlete triad syndrome [Abstract]. Harefuah 151(2), 97-101, 127, 126. Retrieved October 17, 2012, from PubMed database on the World Wide Web: http//www.pubmed.gov.

18. Wang, Ailan. (1993, styczeń). Research on the growth regularity of competitive rhythmic gymnastics athletes [Abstract]. Journal of Xi'an Institute of Physical Education 01. Retrieved October 17, 2012, from Google Scholar database on the World Wide Web: http//www.scholar.google.pl DOI: 1001-747X.0.1993-01-003

19. Theodoropoulou, A., Markou K., Vagenakis G., Benardot D., Leglise M. \& Kourounis G. (2005). Delayed but Normally Progressed Puberty Is More Pronounced in Artistic Compared with Rhythmic Elite Gymnasts Due to the Intensity of Training. ICEM 90(11), 6022-6027.

20. Daly Robin, M., Caine D., Bass Sh. L., Pieter W. \& Broekhoff J. (2005). Growth of highly versus moderately trained competitive female artistic gymnasts. MSSE 37(6), 1053-1060.

21. Jaworowski, J., Lyakh V. \& Wieczorek T. (2009). Genetic and environmental impact on the variability level of somatic and motor development in the course of ontogenetic development in families from the Ostrowiecki Region. Pol. J. Sport Tourism 16, 101-114.

22. Xiu-Wen, G. (2004, maj). Effects of rule change on scientific identification of rhythmic gymnasts [Abstract]. Journal of Beijing University of Physical Education 05. Retrieved October 17, 2012, from Google Scholar database on the World Wide Web: http//www.scholar.google.pl DOI:1007-3612.0. 2004-05-044

23. Rutkowska-Kucharska, A., Szpala A. \& Pieciuk A. (2009). Symmetry of muscle activity during abdominal exercises. Acta of Bioengineering and Biomechanics 11(1), 25-30.

Submitted: December 3, 2012

Accepted: December 20, 2012 